\title{
Phase I study of nanoliposomal irinotecan (PEP02) in advanced solid tumor patients
}

\author{
T. C. Chang $\cdot$ H. S. Shiah $\cdot$ C. H. Yang $\cdot$ K. H. Yeh $\cdot$ \\ A. L. Cheng $\cdot$ B. N. Shen $\cdot$ Y. W. Wang $\cdot$ C. G. Yeh $\cdot$ \\ N. J. Chiang $\cdot$ J. Y. Chang $\cdot$ L. T. Chen
}

Received: 8 July 2014 / Accepted: 30 December 2014 / Published online: 11 January 2015

(c) The Author(s) 2015. This article is published with open access at Springerlink.com

\begin{abstract}
Purpose To define the dose-limiting toxicity (DLT), maximum tolerated dose (MTD) and pharmacokinetics (PK) of PEP02, a novel liposome-encapsulated irinotecan, in patients with advanced refractory solid tumors.

Methods Patients were enrolled in cohorts of one to three to receive escalating dose of PEP02 in a phase I trial. PEP02, from 60 to $180 \mathrm{mg} / \mathrm{m}^{2}$, was given as a 90-min intravenous infusion, every 3 weeks.

Results A total of 11 patients were enrolled into three dose levels: 60 (one patient), 120 (six patients) and $180 \mathrm{mg} / \mathrm{m}^{2}$
\end{abstract}

T. C. Chang and H. S. Shiah have contributed equally to this work.

PEP02 is designated as MM-398 by Merrimack Pharmaceuticals, Inc. (Cambridge, MA, USA).

T. C. Chang

Department of Gynecology, Linkuo Chang-Gung Memorial Hospital, No.5, Fu-Hsing Street, Kuei-shan Hsiang,

Taoyuan 33305, Taiwan

\section{H. S. Shiah}

Cancer Center, Taipei Medical University Hospital, No.252, Wu Hsing Street, Taipei 110, Taiwan

C. H. Yang · K. H. Yeh · A. L. Cheng

Department of Oncology, National Taiwan University Hospital,

No.1, Changde Street, Zhongzheng District, Taipei 10048,

Taiwan

\section{A. L. Cheng}

Department of Internal Medicine, National Taiwan University Hospital, No.1, Changde Street, Zhongzheng District,

Taipei 10048, Taiwan

B. N. Shen $\cdot$ Y. W. Wang $\cdot$ C. G. Yeh

PharmaEngine, Inc., 16F, 237 Sung-Chiang Road, Taipei 104,

Taiwan (four patients). DLT was observed in three patients, one at $120 \mathrm{mg} / \mathrm{m}^{2}$ (grade 3 catheter-related infection) and two at $180 \mathrm{mg} / \mathrm{m}^{2}$ (grade 4 neutropenia lasting for $>3$ days in one, grade 4 hematological toxicities and grade 4 diarrhea in the other). MTD was determined as $120 \mathrm{mg} / \mathrm{m}^{2}$. Comparing with those after free-form irinotecan in the literature, the dose-normalized $\mathrm{PK}$ of $\mathrm{SN}-38$ (the active metabolite) after PEP02 was characterized by lower $C_{\max }$, prolonged terminal half-life and higher AUC but with significant inter-individual variation. One patient who died of treatment-related toxicity had significantly higher $C_{\max }$ and AUC levels of SN-38 than those of the other three patients at $180 \mathrm{mg} / \mathrm{m}^{2}$. Post hoc pharmacogenetic study showed that the patient had a combined heterozygosity genotype

N. J. Chiang · J. Y. Chang $(\bowtie) \cdot$ L. T. Chen $(\bowtie)$

National Institute of Cancer Research, National Health Research Institutes, No. 367, Sheng Li Road, Tainan 70456, Taiwan

e-mail: jychang@nhri.org.tw

L. T. Chen

e-mail: leochen@nhri.org.tw

N. J. Chiang $\cdot$ J. Y. Chang $\cdot$ L. T. Chen

Division of Hematology/Oncology, Department of Internal Medicine, National Cheng Kung University Hospital, College of Medicine, National Cheng Kung University, No.138, Shengli

Road, Tainan 70456, Taiwan

\section{N. J. Chiang $\cdot$ L. T. Chen}

Department of Internal Medicine and Cancer Center, Kaohsiung Medical University Hospital, Kaohsiung Medical University, No.100, Tzyou 1st Road, Kaohsiung 807, Taiwan 
of $U G T 1 A 1 * 6 / * 28$. Two patients had objective tumor response.

Conclusions PEP02 apparently modified the PK parameters of irinotecan and $\mathrm{SN}-38$ by liposome encapsulation. The MTD of PEP02 monotherapy at 3-week interval is $120 \mathrm{mg} / \mathrm{m}^{2}$, which will be the recommended dose for future studies.

Keywords Irinotecan sucrosofate - Liposome - PEP02 . MM-398 · Pharmacokinetics · UGT1Al gene

\section{Introduction}

It has been shown that topoisomerase-I (Topo I) is overexpressed in several cancer types, including breast, lung and colorectal cancers [1]. Irinotecan (CPT-11) is a watersoluble semisynthetic inhibitor of Topo I derived from camptothecin-a plant (Camptotheca acuminata) alkaloid, which can be converted to a more potent metabolite, $\mathrm{SN}-38$, by carboxylesterase primarily in the liver. $\mathrm{SN}-38$ can also be inactivated through glucuronidation by UDPglucuronosyl transferase 1A1 (UGT1Al) to form SN-38G, which is mainly eliminated via biliary excretion. Both CPT11 and SN-38 can bind to Topo I-DNA complex to interfere with the re-ligation of Topo I-induced single-strand DNA breaks and produce double-strand DNA damage during DNA synthesis [2]. Of them, $\mathrm{SN}-38$ is approximately 100 to 1,000 times more potent than the CPT-11 as a Topo I inhibitor. Unfortunately, the metabolic conversions contribute to notable heterogeneities in both toxicity and efficacy of CPT-11, which lead to a rather narrow therapeutic index.

A liposome is a bilayer membrane spherical drug carrier vesicle that enables slow release of encapsulated drug so as to (1) lower drug elimination to prolong systemic circulation time, (2) lower maximum plasma concentration $\left(C_{\max }\right)$ to reduce drug-associated side effects and (3) preferentially pass through the relatively large vascular pore openings in tumors to enhance its local accumulation in tumor tissue [3]. It has been known that both CPT-11 and SN-38 exist in a $\mathrm{pH}$-dependent equilibrium between an inactive carboxylate form and an active lactone form after intravenous injection, and an acidic $\mathrm{pH}$ circumstance, for example in tumor microenvironment, will promote the formation of the active lactone form. Therefore, a liposome-encapsulated formulation will theoretically be able to shift the equilibrium toward more active lactone form formation within tumor tissue to enhance the treatment efficacy of CPT-11.

PEP02 is a novel nanoparticle formulation of irinotecan sucrosofate encapsulated with polyethylene glycolated liposome. The coupling of high molecular weight polyethylene-glycol (PEG) on the surface of PEP02 can effectively protect it from circulating protein binding and subsequent phagocytosis of the reticuloendothelial system to further enhance its circulation time. In preclinical animal studies, PEP02 showed improved preclinical pharmacokinetic properties and anti-tumor activity (in house data) [4]. Herein, we report the results of the first-in-human, phase I trial for PEP02 in patients with refractory advanced solid tumors. The objectives were to identify the maximum tolerated dose (MTD), dose-limiting toxicities (DLT) and safety profile, and to characterize the variables of pharmacokinetics (PK) of PEP02 administered as 90-min infusion every 3 weeks.

\section{Methods}

Trial design and patients

This trial was a multi-center, first-in-human, open-label, phase I, dose-escalation study of PEP02 (liposomeencapsulated irinotecan, PharmaEngine, Inc., Taipei, Taiwan), in patients with advanced refractory solid tumors. Patients with histologically confirmed advanced solid tumors that were refractory to standard systemic chemotherapy were eligible. Further inclusion criteria were age $\geq 20$ years, Eastern Cooperative Oncology Group (ECOG) performance score of 0 or 1 , life expectancy of more than 12 weeks and adequate bone marrow, hepatic and renal functions within 1 week before commencing treatment (hemoglobin $\geq 10 \mathrm{~g} / \mathrm{dL}$, absolute neutrophil count $\geq 1.5 \times 10^{3} / \mathrm{mL}$, platelets $\geq 100 \times 10^{3} / \mathrm{mL}$, serum bilirubin within normal limit, ALT $\leq 2.5 \times$ upper limit of normal, creatinine within normal limit). All prior active treatments, including major surgery, chemotherapy, radiotherapy (except palliative) or endocrine therapy, had to be ceased at least 4 weeks, and all treatment-related toxicities had to be resolved to no greater than grade 1 before enrollment. Patients with central nervous system metastases, pregnancy, uncontrolled active infection or other concomitant serious diseases and who had previously received irinotecan were excluded. All patients gave written informed consent. The trial was approved by the independent ethics committee of each participating institute and the Department of Health, Executive Yuan, Taiwan, and performed in accordance with International Conference on Harmonization Good Clinical Practice guidelines, Good Clinical Laboratory Practice and the Declaration of Helsinki.

Treatment and assessment

PEP02 was diluted in $500 \mathrm{ml}$ of $5 \%$ dextrose and delivered as a 90 -min intravenous infusion, every 21 days. Infusion time was allowed to be prolonged for acute infusion-associated reactions or any other clinical needs. Pre-medication 
included dexamethasone and serotonin-antagonist. Prophylactic anticholinergic agent was not given unless acute cholinergic reaction was observed in prior cycle of treatment. Anti-diarrhea agents were given according to the guideline of American Society of Clinical Oncology. After the infusion of PEP02, vital signs including blood pressure, pulse rate, respiratory rate and body temperature were monitored every $15 \mathrm{~min}$ for $3 \mathrm{~h}$. Detailed history evaluation, vital signs recording, physical examination, complete blood count with differential classification and blood biochemistry tests were performed before treatment and weekly throughout treatment. Toxicity was recorded according to the National Cancer Institute-Common Toxicity Criteria (NCI-CTC) version 3.0, and a DLT was defined as any of the following events: grade 4 hematological toxicity lasting for longer than 3 days; febrile neutropenia; or >grade 3 non-hematological toxicity (except nausea and vomiting).

The starting dose of PEP02 was $60 \mathrm{mg} / \mathrm{m}^{2}$ (level I) based on the 1/10 of the LD10 in mice (the dose lethal to $10 \%$ tested mice) and then would be escalated by $100 \%$ (120 mg/m², level II), $50 \%$ (180 mg/m2, level III), $33 \%$ (240 mg/m $\mathrm{m}^{2}$, level IV), $25 \%$ (300 mg/m $/ \mathrm{m}^{2}$, level V), $16.7 \%$ (350 mg/m², level VI), and $11.4 \%$ (400 mg/m $/ \mathrm{m}^{2}$, level VIII), subsequently. The study was in a modified patient cohort accelerated titration design, in which single-patient cohorts for dose levels I-II, two-patient cohorts for levels III-IV and three-patient cohorts for level $\mathrm{V}$ or above would be recruited until any DLT was observed in the first cycle [5]. If a patient experienced any DLT, then additional patients would be recruited into that cohort. Dose escalation would be stopped if two or more of the patients experienced any DLT, and the prior dose level would be considered as the MTD. A minimum of six patients were required to be tested at the dose level defined as the MTD.

For patients who experienced grade 4 neutropenia and/or $\geq$ grade 3 non-hematological toxicity, the dose of PEP02 would be reduced by one dose level in their subsequent cycle of treatment. Patients would receive PEP02 for a maximum of six courses, or until the presence of disease progression, unacceptable toxicity, treatment delay for $\geq 2$ weeks, or patient's refusal or death. Patients with tumor response or stable disease after six cycles of treatment could receive further PEP02 therapy in a compassionate use expansion program.

Imaging studies consisting of computed tomography of the abdomen and/or chest were performed before and after every two courses of chemotherapy to evaluate tumor response, which was determined according to the RECIST version 1.0 guidelines [6]. All complete and partial responses required confirmation by two consecutive observations no $<4$ weeks apart. Patients with a rapid objective or symptomatic progression before the next course of treatment were considered to have progressive disease (PD).

\section{Pharmacogenetic sampling and analyzing}

Pharmacokinetic testing was done during the first course of PEP02 administration. Blood samples were collected before treatment, during the infusion at 30 and $60 \mathrm{~min}$, at the end of infusion, and after infusion at 1, 2, 3, 6, 9, 12, 24, 48, 72 and $168 \mathrm{~h}$. Plasma levels of encapsulated irinotecan, total irinotecan and SN-38 were determined by validated LC/MS/MS analytical methods. Pharmacokinetic parameters of individual data sets were analyzed by a noncompartmental model using WinNonlin Professional version 4.1 (Pharsight Corporation, Menlo Park, CA).

Peak concentration in plasma $\left(C_{\max }\right)$ and the time to achieve $C_{\max }\left(T_{\max }\right)$ were determined directly by a visual analysis of the individual observed plasma concentration versus time curve data. Area under the plasma concentration-time curve from time zero to infinity $\left(\mathrm{AUC}_{0 \rightarrow \infty}\right)$ was determined by the trapezoidal rule and extrapolated to infinity, which was estimated by the last quantifiable concentration divided by the terminal elimination rate constant $\lambda_{\mathrm{Z}}\left(K_{\mathrm{el}}\right) \cdot \lambda$ was determined by a simple log-linear regression based on the last three points of plasma concentration. Total clearance of drug from plasma $(\mathrm{Cl})$ was determined by the dose divided by the AUC. Plasma terminal elimination half-life $\left(t_{1 / 2}\right)$ was calculated by dividing $\lambda$ into the natural logarithm of two. Mean residence time from time zero to infinity $\left(\mathrm{MRT}_{0 \rightarrow \infty}\right)$ was calculated from the area under the first moment curve from time zero to infinity $\left(\mathrm{AUMC}_{0 \rightarrow \infty}\right)$ divided by $\mathrm{AUC}_{0 \rightarrow \infty}$. Volume of distribution at steady state $\left(V_{\mathrm{ss}}\right)$ was determined by MRT $\times \mathrm{Cl}$.

\section{Statistical analysis}

The association between discrete variables was assessed using Fisher's exact test. The two-tailed Wilcoxon rank sum test was used for the comparison of pharmacokinetic parameters. A value of $p<0.05$ was considered statistically significant.

\section{Results}

Patient characteristics, dose escalation, DLT and MTD

Between January 2005 and August 2005, a total of 11 patients (median age 47, range 41-67 and ECOG PS of 0 or 1) were enrolled. The demographics and baseline characteristics of all patients are listed in Table 1 . These patients were enrolled into three dose levels, with 1, 6 and 4 patients in dose level I, II and III, respectively (Table 2). Initially, none of the first two patients who were separately enrolled at dose level I and level II experienced a DLT. In dose level III $\left(180 \mathrm{mg} / \mathrm{m}^{2}\right)$, because one of the three patients (Patient 
Table 1 Patient characteristics

\begin{tabular}{ll}
\hline Characteristic & Patients, $n(\%)$ \\
\hline Patients enrolled & 11 \\
Age (years) & \\
Median & 47 \\
Range & $41-67$ \\
Sex & \\
Male & $1(9)$ \\
Female & $10(91)$ \\
ECOG performance status & \\
0 & $6(55)$ \\
1 & $5(45)$ \\
Tumor type & \\
Cervical cancer & $4(36)$ \\
Breast cancer & $2(18)$ \\
Neuroendocrine tumor & $2(18)$ \\
Pancreatic cancer & $1(9)$ \\
Non-small cell lung cancer & $1(9)$ \\
Thymic carcinoma & $1(9)$ \\
Previous treatment & \\
Surgery & $9(82)$ \\
Radiotherapy & $8(73)$ \\
Chemotherapy & $11(100)$ \\
\hline
\end{tabular}

Table 2 Dose-escalation schedule and enrolled patient number

\begin{tabular}{llll}
\hline Dose level & Dose $\left(\mathrm{mg} / \mathrm{m}^{2}\right)$ & $\begin{array}{l}\text { Proposed patient } \\
\text { numbers }\end{array}$ & $\begin{array}{l}\text { Actual patient } \\
\text { numbers }\end{array}$ \\
\hline I & 60 & 1 & 1 \\
II & 120 & 1 & 6 \\
III & 180 & 2 & 4 \\
IV & 240 & 2 & 0 \\
V & 300 & 3 & 0 \\
VI & 350 & 3 & 0 \\
VII & 400 & 3 & 0 \\
\hline
\end{tabular}

\#103) developed a DLT (grade 4 neutropenia lasting for longer than 3 days), the study cohort was expanded. The first additionally enrolled patient (Patient \#203) also had DLTs (grade 4 febrile neutropenia, grade 4 thrombocytopenia with bleeding event and grade 4 diarrhea) so that dose escalation was stopped and five more patients were enrolled at dose level II $\left(120 \mathrm{mg} / \mathrm{m}^{2}\right)$. Among the total of 6 patients at dose level II, only one patient (Patient \#205) experienced a DLT (grade 3 catheter-related infection); thus, $120 \mathrm{mg} / \mathrm{m}^{2}$ was determined to be the MTD.

Drug delivery and adverse events

A total of 40 courses of chemotherapy were delivered, with a median of four courses per patient (range, 1-6 courses).
Treatment delay and dose modification were required in 5 $(45.5 \%)$ and $2(18.2 \%)$ patients, respectively. Of the latter two patients, one had dose reduction from 180 to $120 \mathrm{mg} /$ $\mathrm{m}^{2}$ and to $60 \mathrm{mg} / \mathrm{m}^{2}$ because of hematological toxicities, and the other from 120 to $60 \mathrm{mg} / \mathrm{m}^{2}$ due to grade 3 nausea and vomiting. Table 3 shows the drug-related adverse events experienced in at least two patients. The most common toxicity observed in the six patients at the MTD dose level $\left(120 \mathrm{mg} / \mathrm{m}^{2}\right)$ was diarrhea $(100 \%$ in all grades, $33 \%$ in grade 3/4) and vomiting (83.3\% in all grades, $66.7 \%$ in grade $3 / 4$ ). There was no anaphylactic allergic or severe infusion reaction occurred in this phase I study. Only one (\#301) patient experienced chest tightness after $30 \mathrm{~min}$ of infusion during cycle 2 treatment, but corresponding vital signs were stable. No other infusion reactions were reported on the following cycle.

There was one treatment-related death at dose level III (180 mg/m2). A 67-year-old female patient (Patient \#203) with poorly differentiated neuroendocrine tumor (small cell carcinoma) of the pancreas developed severe watery diarrhea and neutropenic fever (WBC and ANC of 360 and 4/ $\mathrm{mm}^{3}$, respectively) 8 days after her first dosing of PEP02. Despite empiric antibiotics, granulocyte-colony stimulating factor (G-CSF) and anti-diarrhea therapy, she died of septic shock, disseminated intravascular coagulopathy and acute respiratory distress syndrome 7 days later. The event was likely related to the alterations of PEP02 PK secondary to the presence of combined heterozygosity of irinotecan metabolism-related genetic polymorphisms of UGT1Al as described later.

Pharmacokinetic and exploratory pharmacogenetic studies

The PK of PEP02 is listed in Table 4 and graphed in Fig. 1a, b. The PK parameters of CPT-11 PEP02 dosing, i.e., after $120 \mathrm{mg} / \mathrm{m}^{2}$, were characterized by slow clearance $\left(\right.$ mean $=0.0591 \mathrm{~L} / \mathrm{m}^{2} / \mathrm{h}$ ), small volume of distribution (mean $=1.8 \mathrm{~L} / \mathrm{m}^{2} \cong$ plasma volume) and prolonged terminal half-life (mean $=29.5 \mathrm{~h}$ ). In addition, the plasma concentration-time profile of encapsulated irinotecan (PEP02) in each patient matched approximately with that of total irinotecan (Fig. 2). The results suggest that the release of irinotecan from liposomes occurred slowly over time. The $C_{\max }$, terminal $t_{1 / 2}$ and AUC of SN-38 after $120 \mathrm{mg} / \mathrm{m}^{2}$ of PEP02 were $9.2 \pm 3.5 \mathrm{ng} / \mathrm{mL}, 75.4 \pm 43.8 \mathrm{~h}$ and $710 \pm 395 \mathrm{ng} * \mathrm{~h} / \mathrm{mL}$, respectively. However, the correlations between $C_{\max }$ or $\mathrm{AUC}_{0-\infty}$ of $\mathrm{SN}-38$ and PEP02 doses were weak $\left(r^{2}=0.423\right.$ for $C_{\max }$ vs. PEP02 dose; $r^{2}=0.0652$ for $\mathrm{AUC}_{0-\infty}$ vs. PEP02 dose). The elimination of SN-38 was much slower and presented larger interindividual variability than those of PEP02 and irinotecan. With the small number of patients and interpatient variability, it is difficult to conclude the dose-proportionality PK 
Table 3 Drug-related adverse events

\begin{tabular}{|c|c|c|c|c|c|c|}
\hline & \multicolumn{2}{|l|}{$\begin{array}{l}60 \mathrm{mg} / \mathrm{m}^{2} \\
N=1\end{array}$} & \multicolumn{2}{|c|}{$\begin{array}{l}120 \mathrm{mg} / \mathrm{m}^{2} \\
N=6\end{array}$} & \multicolumn{2}{|c|}{$\begin{array}{l}180 \mathrm{mg} / \mathrm{m}^{2} \\
N=4\end{array}$} \\
\hline & $\begin{array}{l}\text { All grade } \\
N(\%)\end{array}$ & $\begin{array}{l}\mathrm{G} 3 / 4 \\
N(\%)\end{array}$ & $\begin{array}{l}\text { All grade } \\
N(\%)\end{array}$ & $\begin{array}{l}\mathrm{G} 3 / 4 \\
N(\%)\end{array}$ & $\begin{array}{l}\text { All grade } \\
N(\%)\end{array}$ & $\begin{array}{l}\text { G 3/4 } \\
N(\%)\end{array}$ \\
\hline Diarrhea & $1(100)$ & $0(0)$ & $6(100)$ & $2(33.3)$ & $4(100)$ & $1(25)$ \\
\hline Vomiting & $1(100)$ & $0(0)$ & $5(83.3)$ & $4(66.7)$ & $2(50)$ & $2(50)$ \\
\hline Nausea & $1(100)$ & $0(0)$ & $4(66.7)$ & $2(33.3)$ & $2(50)$ & $1(25)$ \\
\hline Alopecia & $0(0)$ & NA & $3(50)$ & NA & $3(75)$ & NA \\
\hline Fatigue & $1(100)$ & $0(0)$ & $3(50)$ & $1(16.7)$ & $1(25)$ & $0(0)$ \\
\hline Leukopenia & $0(0)$ & $0(0)$ & $2(33.3)$ & $1(16.7)$ & $2(50)$ & $2(50)$ \\
\hline Neutropenia & $0(0)$ & $0(0)$ & $2(33.3)$ & $1(16.7)$ & $2(50)$ & $2(50)$ \\
\hline Weight decreased & $1(100)$ & $0(0)$ & $2(33.3)$ & $0(0)$ & $1(25)$ & $0(0)$ \\
\hline Dizziness & $0(0)$ & $0(0)$ & $2(33.3)$ & $0(0)$ & $0(0)$ & $0(0)$ \\
\hline Anemia & $0(0)$ & $0(0)$ & $1(16.7)$ & $0(0)$ & $1(25)$ & $0(0)$ \\
\hline Anorexia & $0(0)$ & $0(0)$ & $1(16.7)$ & $0(0)$ & $1(25)$ & $0(0)$ \\
\hline Electrolyte imbalance & $0(0)$ & $0(0)$ & $1(16.7)$ & $0(0)$ & $1(25)$ & $0(0)$ \\
\hline
\end{tabular}

of CPT-11 between the three dose levels. However, higher AUC was observed at higher dose levels.

The $\mathrm{AUC}_{0-\infty}$ and $C_{\max }$ of CPT-11 and SN-38 of the patient who died of treatment-related complications (Patient \#203) were investigated as shown in Fig. 3a, b. The $\mathrm{AUC}_{0-\infty}$ and $C_{\text {max }}$ of SN-38 of patient \#203 were 2-3 folds higher than those of the other three patients receiving the same dose of treatment. To explore the potential genetic background for the differences, the irinotecan metabolism-related genetic polymorphisms of patients receiving $180 \mathrm{mg} / \mathrm{m}^{2}$ were determined after the approval of IRB. Three of the four patients with available stocked peripheral blood mononuclear cells were included in the pharmacogenetic study, which showed that the patient (Patient \#203) who died of treatment-related toxicity had combined heterozygosity of $U G T 1 A 1 * 6 / * 28$ (Table 5).

\section{Efficacy}

The best tumor response was partial response in two out of 11 intent-to-treat (ITT) patients $(18.2 \%)$ or out of ten response evaluable patients $(20 \%)$. One patient with pancreatic cancer who failed to several lines of treatment including gemcitabine and infusional 5FU/LV alone or in combination with oxaliplatin had PEP02 at the dose of $180 \mathrm{mg} / \mathrm{m}^{2}$, and the other one with cervical cancer whose tumor relapsed after cisplatin-based concurrent chemoradiotherapy had PEP02 at the dose of $120 \mathrm{mg} / \mathrm{m}^{2}$. Another three patients with breast cancer, pancreatic neuroendocrine tumor and thymic carcinoma in each had stable disease. Therefore, the disease control rate was $45.5 \%$ for ITT population or $50 \%$ for response evaluable patients. At the MTD dose of $120 \mathrm{mg} / \mathrm{m}^{2}, 5$ out of 6 patients were evaluable for tumor response. One patient (\#205) with squamous cell carcinoma of the lung who was early off-studied because of prolonged treatment interruption secondary to DLT (grade 3 catheter-related infection) was excluded from response evaluation. The response rate and disease control rate of evaluable patients were 20 and $60 \%$, respectively. However, the unevaluable patients (\#205) received five additional courses of PEP02 at $120 \mathrm{mg} / \mathrm{m}^{2}$ after adequate infection control and achieved a partial response under the compassionate use program.

\section{Discussion}

The current study has established the MTD, safety profile, PK and preliminary efficacy of PEP02, a nanoliposomal formulation of irinotecan, in patients with refractory advanced cancer. Myelosuppression and diarrhea were the major DLTs, and $120 \mathrm{mg} / \mathrm{m}^{2}$ was defined as the MTD. The toxicity pattern seems to be comparable with that of free-form irinotecan [7, 8]. Of note, in the absence of prophylactic atropine administration, there was only one episode of grade 1 acute cholinergic syndrome (abdominal pain) observed in this study, as compared to the occurrence in 9 of 23 patients who received free irinotecan $\geq 240 \mathrm{mg} / \mathrm{m}^{2}$ in a phase I trial [9]. It has been shown that irinotecan may inhibit acetyl-cholinesterase to enhance parasympathetic discharge, and the frequency and severity of cholinergic syndrome are likely irinotecan concentration dependent [10, 11].

In the current study, pharmacokinetic analysis demonstrated that the plasma concentration-time profile of PEP02 (encapsulated irinotecan) in each patient matched approximately with that of total irinotecan, indicating that the release of free-form irinotecan from the nanoliposomes occurred slowly over time. We were not able to measure 
Table 4 Pharmacokinetic parameters of PEP02 at each dose level

\begin{tabular}{|c|c|c|c|c|c|c|c|c|c|}
\hline & $\begin{array}{l}\text { Dose level } \\
\left(\mathrm{mg} / \mathrm{m}^{2}\right)\end{array}$ & $\begin{array}{l}C_{\max } \\
(u \mathrm{~g} / \mathrm{mL}) \\
\text { CPT-11(ng / } \\
\mathrm{mL}) \\
\mathrm{SN}-38\end{array}$ & $\begin{array}{l}T_{\max } \\
(\mathrm{hr})\end{array}$ & $\begin{array}{l}\mathrm{AUC}_{0-169.5} \\
(\mathrm{hr}-u \mathrm{~g} / \mathrm{mL}) \\
\text { CPT-11 } \\
\text { (hr-ng/mL) } \\
\text { SN-38 }\end{array}$ & $\begin{array}{l}\mathrm{AUC}_{0-\infty} \\
(\mathrm{hr}-u \mathrm{~g} / \mathrm{mL}) \\
\text { CPT-11 } \\
\text { (hr-ng/mL) } \\
\text { SN-38 }\end{array}$ & $\begin{array}{l}V_{\mathrm{ss}} \\
\left(\mathrm{L} / \mathrm{m}^{2}\right)\end{array}$ & $\begin{array}{l}\mathrm{Cl} \\
(\mathrm{L} / \mathrm{hr} / \mathrm{m} 2)\end{array}$ & $\begin{array}{l}t_{1 / 2} \\
(\mathrm{hr})\end{array}$ & $\begin{array}{l}\mathrm{MRT}_{0-\infty} \\
(\mathrm{hr})\end{array}$ \\
\hline \multirow{3}{*}{$\begin{array}{l}\text { Total } \\
\text { CPT-11 }\end{array}$} & $60, N=1$ & 31.8 & 1.5 & 222 & 223 & 3.56 & 0.269 & 28.7 & 13.2 \\
\hline & $120, N=6$ & $79.4 \pm 13.9$ & $2.5 \pm 1.1$ & $2,835 \pm 1,817$ & $2,963 \pm 1,947$ & $1.8 \pm 0.771$ & $0.0591 \pm 0.0367$ & $29.5 \pm 17.2$ & $38.6 \pm 19.5$ \\
\hline & $180, N=4$ & $102 \pm 17.6$ & $1.75 \pm 0.5$ & $1,945 \pm 1,029$ & $1,963 \pm 1,035$ & $1.97 \pm 0.342$ & $0.119 \pm 0.0703$ & $22.3 \pm 11.5$ & $20.5 \pm 9.47$ \\
\hline \multirow[t]{3}{*}{$\mathrm{SN}-38$} & $60, N=1$ & 2.58 & 3.6 & 38.4 & $\mathrm{NC}$ & NA & NA & $\mathrm{NC}$ & $\mathrm{NC}$ \\
\hline & $120, N=6$ & $9.20 \pm 3.50$ & $21.9 \pm 26.3$ & $710 \pm 395$ & $997 \pm 680$ & NA & NA & $75.4 \pm 43.8$ & $109.0 \pm 54.4$ \\
\hline & $180, N=4$ & $14.3 \pm 6.16$ & $21.0 \pm 9.0$ & $1,159 \pm 969$ & $1,425 \pm 1,134$ & NA & NA & $58.0 \pm 32.8$ & $90.9 \pm 43.1$ \\
\hline
\end{tabular}

Mean $\pm \mathrm{SD} ; C_{\max }$ peak concentration in plasma; $T_{\max }$ time to achieve peak plasma concentration; $A U C_{0-169.5}, A U C_{0-\infty}$ area under the plasma concentration-time curve from time zero to $169.5 \mathrm{~h}$ and infinity, respectively; $V_{s s}$ volume of distribution at steady state; $t_{l / 2}$ plasma terminal elimination half-life; $\mathrm{Cl}$ total clearance of drug from plasma; $M R T_{0-\infty}$ mean residence time from time zero to infinity; $N C$ not calculated because there was no distinct terminal log-linear phase for the $\lambda_{\mathrm{z}}$ determination; $N A$ not available

plasma level of free CPT-11 directly because it was below the lower detection limit of the LC/MS/MS assay. The slow release of irinotecan from PEP02 resulted in small volume of distribution (mean $=1.8 \mathrm{~L} / \mathrm{m}^{2} \cong$ plasma volume), slow clearance and prolonged terminal half-life of circulating total irinotecan, and a favorable PK of its active metabolite, SN-38. Comparing the PK of SN-38 in this study with the published studies following administration of $125 \mathrm{mg} /$ $\mathrm{m}^{2}$ free-form irinotecan in the literature, the PK parameters of SN-38 after $120 \mathrm{mg} / \mathrm{m}^{2}$ of PEP02 showed lower $C_{\max }(9.2 \pm 3.5$ vs $26.3 \pm 11.9 \mathrm{ng} / \mathrm{mL})$, longer terminal $t_{1 / 2}$ $(75.4 \pm 43.8$ vs $10.4 \pm 3.1 \mathrm{~h})$ and higher AUC $(710 \pm 395$ vs $229 \pm 108 \mathrm{ng} * \mathrm{~h} / \mathrm{mL})[12,13]$. The AUC of SN-38 after $120 \mathrm{mg} / \mathrm{m}^{2}$ PEP02 was roughly comparable with that achievable with $300-350 \mathrm{mg} / \mathrm{m}^{2}$ of "conventional" irinotecan in the literature. The lower toxicity profile potentially makes PEP02 a better agent to combine with other cytotoxic agents, i.e., 5-fluorouracil and folinic acid, and/or targeted agents, i.e., bevacizumab or cetuximab for advanced colorectal cancer. However, the optimal dosages of PEP02 for such combinations remain to be determined.

The correlations between the $C_{\max }$ or $\mathrm{AUC}_{0-\infty}$ of $\mathrm{SN}-38$ and doses of PEP02 were weak in this phase I study. The elimination of $\mathrm{SN}-38$ was slow and exhibited significant inter-individual variation after administration of PEP02. The reason for such inter-individual variation in kinetic behavior of SN-38 after PEP02 administration is not yet fully explored, but pharmacogenetic variability of irinotecan metabolismrelated enzymes is likely to be involved. The presence of the $U G T 1 A 1 * 28$ allele has been shown to cause a $70 \%$ reduction in the expression of UGT, the enzyme responsible for glucuronidation of SN-38 into inactive SN-38 glucuronide (SN-38G). This reduction leads to increased exposure of patients to the cytotoxic metabolite, SN-38 $[14,15]$. Clinically, patients with either heterozygous $U G T 1 A 1 * 1 / 28$ or
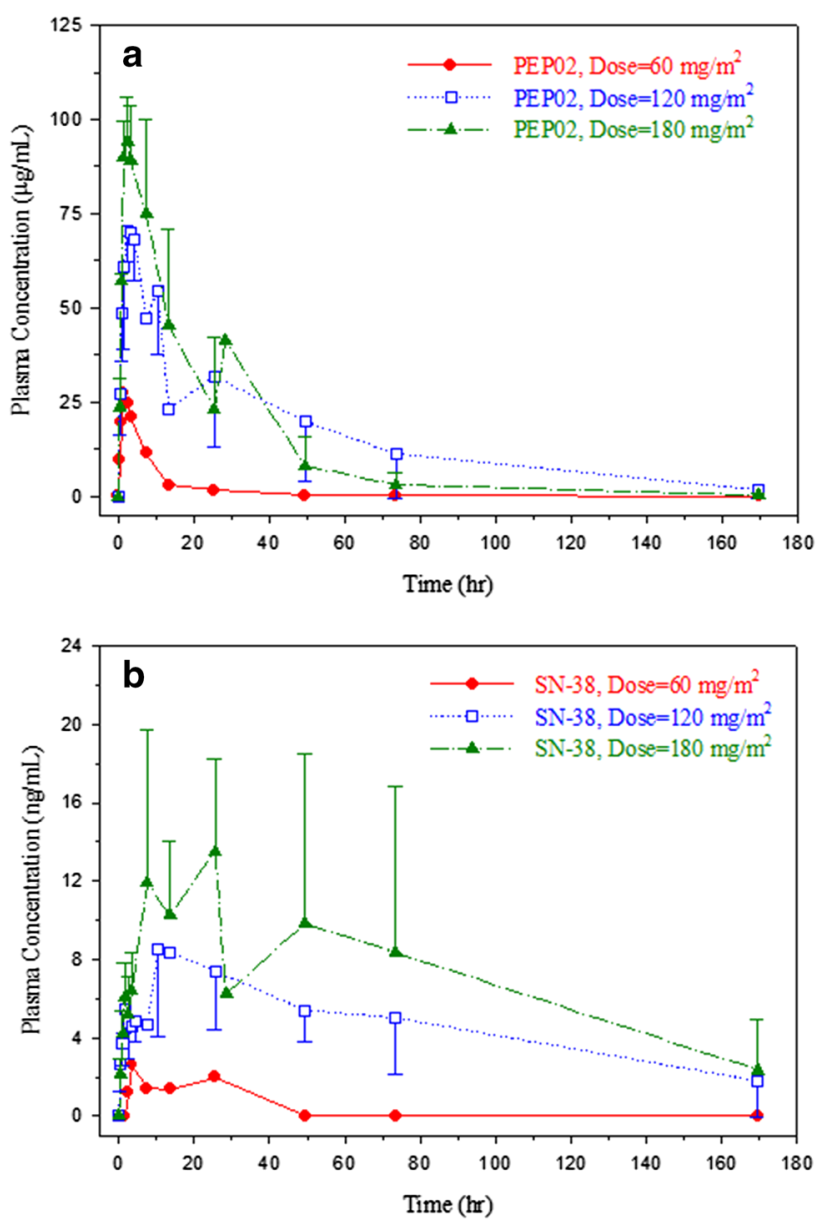

Fig. 1 Plasma concentration-time profiles of a encapsulated CPT-11 (PEP02) and b SN-38 at 60, 120 and $180 \mathrm{mg} / \mathrm{m}^{2}$ dose level of PEP02

homozygous $U G T 1 A 1 * 28 / * 28$ genotypes are more prone to severe irinotecan-associated toxicity, notably grade 3-4 neutropenia and/or diarrhea [15]. Based on these findings, the 


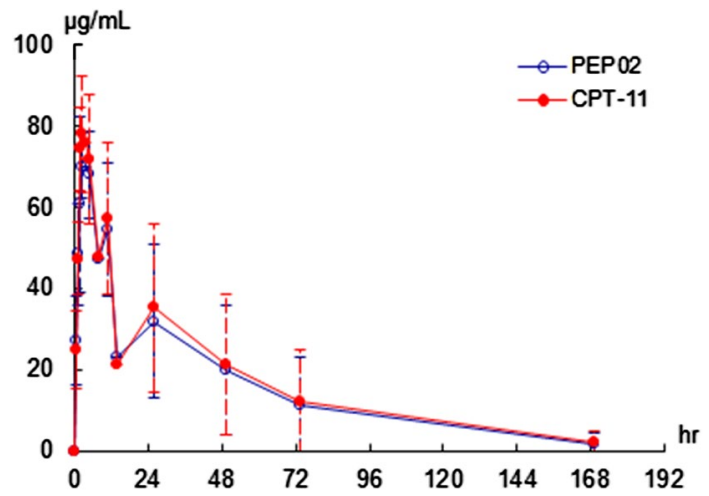

Fig. 2 Plasma concentration-time profiles of encapsulated CPT-11 (PEP02) and total CPT-11 at $120 \mathrm{mg} / \mathrm{m}^{2}$ dose level of PEP02

US Food and Drug Administration revised the label of irinotecan and recommended that patients who are known to be homozygous for the $U G T 1 A I * 28$ allele should receive a reduced initial dose of irinotecan to minimize the risk of significant toxicity [16]. However, ethnic differences in UGTIAI allele frequencies are well established, and the Asian population is known to have a lower frequency of the UGTIAl $* 28$ allele (13.9\% vs $33.4 \%$ in Caucasians) but a significantly higher frequency of $U G T 1 A I * 6(13.0 \%$ vs $0.5 \%$ in Caucasians) [15]. It has been reported that patients with a combined heterozygosity of $U G T I A I * 6$ and $* 28$ were more prone to develop toxicities after irinotecan injection, as happened in one of our patients $[17,18]$. Comparing the PK of SN-38 in the four patients receiving $180 \mathrm{mg} / \mathrm{m}^{2}$ of PEP02, the $C_{\max }$ and $\mathrm{AUC}_{0-\infty}$ of SN-38 of the patient (\#203) who died of grade 4 diarrhea, neutropenia and infection were almost threefold higher than in the other three patients.

Other liposome formulations of irinotecan or $\mathrm{SN}-38$ have also been developed. IHL-305 (pegylated liposomal irinotecan) has been identified in its MTD at every 4 week and every 2 week schedule as 160 and $80 \mathrm{mg} / \mathrm{m}^{2}$, respectively, in a phase I study [19]. The $\mathrm{AUC}_{0-\infty}$ of $\mathrm{SN}-38$ at $160 \mathrm{mg} / \mathrm{m}^{2}$ was $360 \pm 370 \mathrm{ng} * \mathrm{~h} / \mathrm{mL}$, and one PR and two SD were observed among the 60 patients recruited. PEP02 at $120 \mathrm{mg} / \mathrm{m}^{2}$ showed higher SN-38 exposure than IHL-305 at $160 \mathrm{mg} / \mathrm{m}^{2}$. LE-SN38 is a liposome-encapsulated SN-38, which had been developed in phase II stage. The MTD of LE-SN38 was identified in its phase I study as $35 \mathrm{mg} /$ $\mathrm{m}^{2}$ every 3 weeks for both the UGTIAI*28 wild-type and heterozygous patients [20]. The $\mathrm{AUC}_{0-\infty}$ of $\mathrm{SN}-38$ at the MTD for the wild-type and heterozygous patients were 1,751.8 and 3,493.6 $\mathrm{ng} * \mathrm{~h} / \mathrm{mL}$, respectively. Notwithstanding LE-SN38 has relatively high SN-38 AUC, unfortunately, it did not meet the pre-specified activity criteria in its phase II CALGB 80402 study for mCRC patients [21].

Although antitumor activity was not the primary endpoint in this phase I trial, two patients with
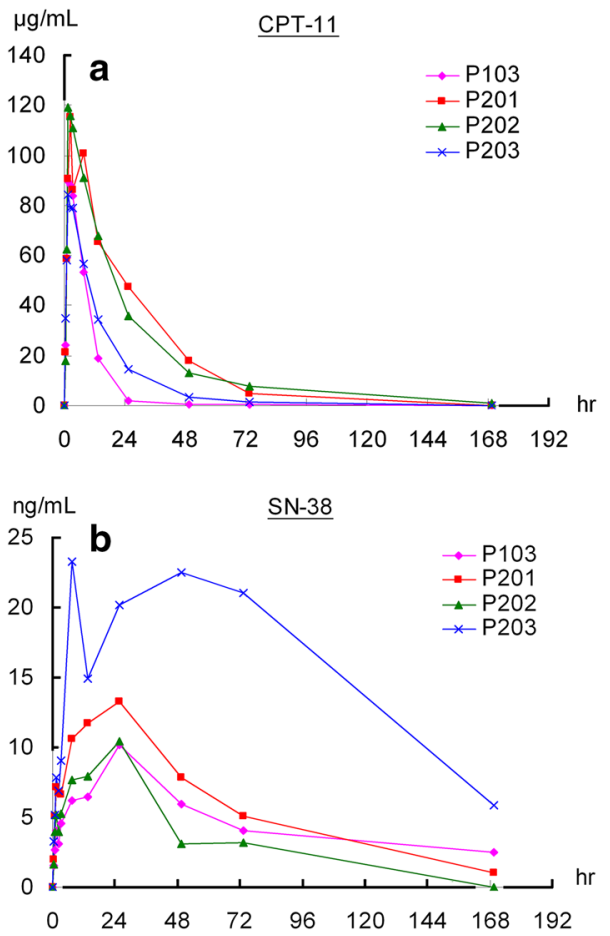

Fig. 3 Plasma concentration-time profiles of $\mathbf{a}$ total CPT-11 and $\mathbf{b}$ $\mathrm{SN}-38$ in subjects at $180 \mathrm{mg} / \mathrm{m}^{2}$ dose level of PEP02

Table 5 Pharmacokinetic parameters of SN-38 and pharmacogenetic data of patients received $180 \mathrm{mg} / \mathrm{m}^{2}$ of PEP02

\begin{tabular}{lcllll}
\hline $\begin{array}{l}\text { Patient } \\
\text { unique } \\
\text { number }\end{array}$ & $\begin{array}{l}\mathrm{AUC}_{0-\infty} \\
(\mathrm{hr}-\mathrm{ng} / \mathrm{mL})\end{array}$ & $\begin{array}{l}C_{\max } \\
(\mathrm{ng} / \mathrm{mL})\end{array}$ & $\begin{array}{l}t_{1 / 2} \\
(\mathrm{hr})\end{array}$ & $\mathrm{UGT1A1}$ *6 & UGT1A1*28 \\
\hline 201 & 906 & 13.3 & 41.4 & $\mathrm{~W} / \mathrm{W}$ & $\mathrm{W} / \mathrm{W}$ \\
202 & 549 & 10.4 & 28.2 & $\mathrm{~W} / \mathrm{W}$ & $\mathrm{W} / \mathrm{W}$ \\
203 & 3,084 & 23.3 & 59.0 & $\mathrm{~V} / \mathrm{W}$ & $\mathrm{V} / \mathrm{W}$ \\
103 & 1,159 & 10.2 & 104 & $\mathrm{ND}$ & $\mathrm{ND}$ \\
\hline
\end{tabular}

$V$ variant; $W$ wild type

$N D$ not done

partial response and three patients with stable disease were observed out of 11 ITT patients. Notably, one patient (\#205) who developed non-drug-related toxicity after the first course and received five additional courses under compassionate use program also had partial response. Several researches investigating the efficacy of PEP02 with or without other anticancer drugs are currently ongoing. In conclusion, the MTD of PEP02 given every 3 weeks is $120 \mathrm{mg} / \mathrm{m}^{2}$, and major treatment-related DLTs are myelosuppression and diarrhea. Promising anti-tumor activities that were observed in the patients who were refractory to available treatments warrant further clinical investigations. 
Acknowledgments This study was supported by PharmaEngine, Inc., Taipei, Taiwan. We thank the patients and their families who participated in this phase I study and also thank the medical and nursing staff of the investigational sites for the care and support of the patients in this study.

Conflict of interest T. C. Chang has received an honorarium from PharmaEngine for an advisory board. H. S. Shiah, C. H. Yang, K. H. Yeh and A. L. Cheng, J. Y. Chang, N. J. Chiang report no conflict of interests. B. N. Shen, Y. W. Wang and C. G. Yeh are full-time employees of PharmaEngine. L. T. Chen has received an honorarium from PharmaEngine for an advisory board.

Ethical standard All patients gave written informed consent prior their inclusion in the study. The trial was approved by the independent ethics committee of each participating institute and the Department of Health, Executive Yuan, Taiwan, and performed in accordance with International Conference on Harmonization Good Clinical Practice guidelines, Good Clinical Laboratory Practice and the Declaration of Helsinki.

Open Access This article is distributed under the terms of the Creative Commons Attribution License which permits any use, distribution, and reproduction in any medium, provided the original author(s) and the source are credited.

\section{References}

1. Costin D, Potmesil M (1994) Preclinical and clinical development of camptothecins. Adv Pharmacol 29B:51-72

2. Iyer L, King CD, Whitington PF, Green MD, Roy SK, Tephly TR, Coffman BL, Ratain MJ (1998) Genetic predisposition to the metabolism of irinotecan (CPT-11). Role of uridine diphosphate glucuronosyltransferase isoform $1 \mathrm{~A} 1$ in the glucuronidation of its active metabolite (SN-38) in human liver microsomes. J Clin Invest 101:847-854

3. Zamboni WC, Jung LL, Egorin MJ, Hamburger DR, Joseph E, Jin R, Strychor S, Ramanathan RK, Eiseman JL (2005) Relationship between plasma exposure of 9-nitrocamptothecin and its 9-aminocamptothecin metabolite and antitumor response in mice bearing human colon carcinoma xenografts. Clin Cancer Res 11:4867-4874

4. Drummond DC, Noble CO, Guo Z, Hong K, Park JW, Kirpotin DB (2006) Development of a highly active nanoliposomal irinotecan using a novel intraliposomal stabilization strategy. Cancer Res 66:3271-3277

5. Simon R, Freidlin B, Rubinstein L, Arbuck SG, Collins J, Christian MC (1997) Accelerated titration designs for phase I clinical trials in oncology. J Natl Cancer Inst 89:1138-1147

6. Therasse P, Arbuck SG, Eisenhauer EA, Wanders J, Kaplan RS, Rubinstein L, Verweij J, Glabbeke MV, Oosterom ATV, Christian MC, Gwyther SG, European Organization for Research and Treatment of Cancer, National Cancer Institute of the United States, National Cancer Institute of Canada (2000) New guidelines to evaluate the response to treatment in solid tumors. J Natl Cancer Inst 92:205-216

7. Cunningham D, Pyrhönen S, James RD, Punt CJ, Hickish TF, Heikkila R, Johannesen TB, Starkhammar H, Topham CA, Awad L, Jacques C, Herait P (1998) Randomised trial of irinotecan plus supportive care versus supportive care alone after fluorouracil failure for patients with metastatic colorectal cancer. Lancet 352:1413-1418
8. Fuchs CS, Moore MR, Harker G, Villa L, Rinaldi D, Hecht JR (2003) Phase III comparison of two irinotecan dosing regimens in second-line therapy of metastatic colorectal cancer. J Clin Oncol 21:807-814

9. Rowinsky EK, Grochow LB, Ettinger DS, Sartorius SE, Lubejko BG, Chen TL, Rock MK, Donehower RC (1994) Phase I and pharmacological study of the novel topoisomerase I inhibitor 7-ethyl-10-[4-(1-piperidino)-1-piperidino] carbonyloxycamptothecin (CPT-11) administered as a ninety-minute infusion every 3 weeks. Cancer Res 54:427-436

10. Harel M, Hyatt JL, Brumshtein B, Morton CL, Yoon KJ, Wadkins RM, Silman I, Sussman JL, Potter PM (2005) The crystal structure of the complex of the anticancer prodrug 7-ethyl-10-[4(1-piperidino)-1-piperidino]-carbonyloxycamptothecin (CPT11) with Torpedo californica acetylcholinesterase provides a molecular explanation for its cholinergic action. Mol Pharmacol 67:1874-1881

11. Blandizzi C, De Paolis B, Colucci R, Lazzeri G, Baschiera F, Del Tacca M (2001) Characterization of a novel mechanism accounting for the adverse cholinergic effects of the anticancer drug irinotecan. Br J Pharmacol 132:73-84

12. Rothenberg ML, Kuhn JG, Burris HA 3rd, Nelson J, Eckardt JR, Tristan-Morales M, Hilsenbeck SG, Weiss GR, Smith LS, Rodriguez GI (1993) Phase I and pharmacokinetic trial of weekly CPT11. J Clin Oncol 11:2194-2204

13. Rivory LP, Haaz MC, Canal P, Lokiec F, Armand JP, Robert J (1997) Pharmacokinetic interrelationships of irinotecan (CPT11) and its three major plasma metabolites in patients enrolled in phase I/II trials. Clin Cancer Res 3:1261-1266

14. Bosma PJ, Chowdhury JR, Bakker C, Gantla S, de Boer A, Oostra BA, Lindhout D, Tytgat GN, Jansen PL, Elferink RP, Chowdhury NR (1995) The genetic basis of the reduced expression of bilirubin UDP-glucuronosyltransferase 1 in Gilbert's syndrome. N Engl J Med 333:1171-1175

15. Palomaki GE, Bradley LA, Douglas MP, Kolor K, Dotson WD (2009) Can UGT1A1 genotyping reduce morbidity and mortality in patients with metastatic colorectal cancer treated with irinotecan: an evidence-based review. Genet Med 11:21-34

16. Camptosar brand of irinotecan hydrochloride injection [package insert]. Pfizer, 2012

17. Araki K, Fujita K, Ando Y, Nagashima F, Yamamoto W, Endo H, Miya T, Kodama K, Narabayashi M, Sasaki Y (2006) Pharmacogenetic impact of polymorphisms in the coding region of the UGT1A1 gene on SN-38 glucuronidation in Japanese patients with cancer. Cancer Sci 97:1255-1259

18. Minami H, Sai K, Saeki M, Saito Y, Ozawa S, Suzuki K, Kaniwa N, Sawada J, Hamaguchi T, Yamamoto N, Shirao K, Yamada Y, Ohmatsu H, Kubota K, Yoshida T, Ohtsu A, Saijo N (2007) Irinotecan pharmacokinetics/pharmacodynamics and UGT1A genetic polymorphisms in Japanese: roles of UGT1A1*6 and *28. Pharmacogenet Genomics 17:497-504

19. Infante JR, Keedy VL, Jones SF, Zamboni WC, Chan E, Bendell JC, Lee W, Wu H, Ikeda S, Kodaira H, Rothenberg ML, Burris HA III (2012) Phase I and pharmacokinetic study of IHL-305 (PEGylated liposomal irinotecan) in patients with advanced solid tumors. Cancer Chemother Pharmacol 5:699-705

20. Kraut EH, Fishman MN, Lorusso PM, Gordon MS, Rubin EH, Haas A, Fetterly GJ, Cullinan P, Dul JL, Steinberg JL (2005) Final results of a phase I study of liposome encapsulated SN-38 (LE-SN38): safety, pharmacogenomics, pharmacokinetics, and tumor response [abstract 2017]. ASCO annual meeting

21. Ocean AJ, Niedzwiecki D, Atkins JN, Parker B, O'Neil BH, Lee JW, Wadler S, Goldberg RM (2008) LE-SN38 for metastatic colorectal cancer after progression on oxaliplatin: results of CALGB 80402 [abstract 4109]. ASCO annual meeting 